\title{
AS FORMAS DE TRATAMENTO E A INTERPRETAÇÃO DA LIBRAS PARA O PORTUGUÊS BRASILEIRO: POLIDEZ E PODER
}

\author{
ADDRESS FORMS AND INTERPRETING \\ FROM LIBRAS TO BRAZILIAN PORTUGUESE: \\ POLITENESS AND POWER
}

\author{
Maria Cristina Pires Pereira \\ Universidade Federal do Rio Grande do Sul, UFRGS, Porto Alegre, RS, Brasil
}

\begin{abstract}
Resumo: Utilizando o fenômeno das formas de tratamento (FT), dentro da interpretação na direcionalidade Libras (língua de sinais brasileira) para o Português Brasileiro (PB), analisei como os intérpretes de línguas de sinais (ILS) referiam-se aos colocutores das pessoas surdas. O estudo foi feito no âmbito de uma instituição de ensino superior, com filmagens de interaçôes reais. A partir da transcriçáo e dos resultados, teci consideraçóes sobre aspectos sociolinguísticos envolvidos nos eventos filmados e sobre a extrema relevância de que os ILS desenvolvam conhecimentos não só linguísticos e discursivos, mas também as habilidades de comunicação intercultural.
\end{abstract}

Palavras-chave: formas de tratamento; línguas de sinais; Libras; línguas orais; português brasileiro.

Abstract: Using the forms of address phenomenon, within the interpretation in the directionality from Libras (Brazilian sign language) to Brazilian Portuguese (BP), I analyzed how sign language interpreters (SLI) refer to the co-speakers of deaf people. The study was carried out in the context of a higher education institution, with footages of real interactions. From the transcription and the results, I made considerations about sociolinguistic aspects involved in the recorded events and about the extreme relevance of the ILS to develop not only linguistic and discursive knowledge, but also intercultural communication skills.

Keywords: address forms; sign languages; Libras; oral languages, Brazilian Portuguese.

\section{Introduçáo}

Os Intérpretes de línguas de sinais (ILS) são, como comunidade de apoio, uma parte muito importante na vida das pessoas surdas. No entanto, 
ainda hoje, o ofício e a sua atuaçáo não são plenamente compreendidos, não só entre os surdos como, até mesmo, dentro da própria categoria. Um destes aspectos, ensinado e perpetuado sem grandes reflexôes e pesquisas, foi como os ILS devem se enunciar ao interpretar da Libras (Língua de Sinais Brasileira) para o Português Brasileiro (PB). Existe, de modo generalizado, e nos mais variados pares linguísticos, o seguinte exemplo de normativa:

Fale em primeira pessoa. Quando interpretar, fale como se você fosse a pessoa que está falando. Por exemplo, se o falante diz: "Eu já paguei esta conta", você deveria interpretar como "Eu já paguei esta conta”. Seu dever é simplesmente repetir [grifo meu] tudo o que é dito (CALIFORNIA COURT, 2008, s. p.). ${ }^{1}$

Interessantemente, não é comum a discussão sobre como nos dirigirmos a quem nos endereçamos, nossos colocutores, fator de extrema importância, principalmente na interpretação de diálogos. Sendo que, na interpretação da Libras para o Português Brasileiro (PB), a maioria das pessoas ouvintes tomam o discurso como a manifestaçáo originária das pessoas surdas, não mediada pela subjetividade dos ILS, de maneira que esse enunciado pode influenciar no sucesso e na percepção dos surdos pela sociedade ouvinte. As línguas possuem diferentes arranjos de como tratar nossos colocutores, dependendo de fatores como a solidariedade e o poder. Estas diferenças têm que ser harmonizadas pelos ILS e, nestas ocasióes, entram em jogo náo só os seus conhecimentos linguístico e discursivo, como também a sua sensibilidade e o tato intercultural.

Optei por abordar a questáo do ponto de vista das formas de tratamento $(\mathrm{FT})^{2}$ por permitir uma abordagem prioritariamente sociolinguística, que possibilite uma aberta conexão entre um fato da língua(gem) e as posturas socioculturais, muito presentes em uma interação mediada como é a interpretação interlíngue. As FT são um elemento de bastante complexidade e se relacionam com as questôes de polidez, manifestadas por meio da língua(gem), regulando as relaçóes interpessoais.

\footnotetext{
${ }^{1}$ No original: Speak in the First Person. When interpreting, speak as if you are the person speaking. For example, if the speaker states, "I already paid that bill," you should interpret it as: "I already paid that bill." Your duty is simply to repeat everything that is said (CALIFORNIA COURT, 2008). Traduçáo livre de Maria Cristina Pires Pereira.

2 Este texto é um extrato adaptado e atualizado de minha tese "A Interpretação Interlíngue da Libras para o Português Brasileiro: um estudo sobre as formas de tratamento".
} 


\section{As Formas de Tratamento: breve retomada teórica}

As formas que utilizamos para nos endereçarmos a outras pessoas e, até a nós mesmos, em uma interação, recebem o nome de formas de tratamento (FT). Os fatores que definem a escolha de uma FT são, principalmente, dois: (1) a relaçáo entre os participantes do ato de linguagem, chamada de indexador social (social indexing), e (2) as intençôes e variáveis sociais, que podem ser chamadas de polidez estratégica (KASPER, 1990).

No clássico trabalho de Brown e Gilman (1960), os autores, além de fazerem uma retrospectiva histórica dos usos de FT entre as classes sociais, marcam dois tipos principais: (T) que identifica a FT de solidariedade, intimidade e reciprocidade entre os interlocutores; e (V) como a marca de superioridade, distância (a quem não é familiar), reverência e, até, elegância (fórmula de modéstia e majestade). Ambas as convençóes são oriundas do Latim, tu e vos. Os endereçamentos ao colocutor com um (T) ou um $(\mathrm{V})$, segundo os autores, depende de fatores de solidariedade e poder. A solidariedade baseia-se no pressuposto de uma relaçáo entre iguais, que se reconhecem como pertencentes, virtualmente, a uma mesma classe (econômica, formação acadêmica, grupo ou associação de classe, etc.) ou, ainda, que concordem, explícita ou implicitamente, em se tratarem como iguais. O poder, por outro lado, é a possibilidade de exercer influência sobre a outra pessoa, de mudar o seu comportamento, tendo como base as relaçóes hierárquicas, dependentes da faixa etária, prestígio, nível econômico e social, entre outros. O poder não é igualitário, sempre alguém é superior ou inferior a outro alguém; não existe reciprocidade.

As alternâncias de FT, durante uma interação, são reguladas pelo tipo de relaçáo, entre os interlocutores, que pode ser simétrica ou recíproca (igual $\rightarrow$ igual, $\mathrm{V} \leftrightarrow \rightarrow \mathrm{V}$ ou $\mathrm{T} \leftrightarrow \rightarrow \mathrm{T}$ ), ou assimétrica ou não-recíproca (superior $->$ inferior, $\mathrm{V}_{\imath \rightarrow \mathrm{T}}$ ).

Em PB, Biderman (1972/1973) faz um dos primeiros apanhados gerais de origem, evolução, uso entre as classes sociais e comparação entre as formas (T) e (V), inclusive em relação a outras línguas latinas, principalmente, o espanhol utilizado em diversos países. Mais recentemente, Modesto (2005) faz um levantamento sobre os estudos sobre as FT no PB, constituindo-se em um verdadeiro estado da arte, até aquele momento.

\section{Critérios de classificaçáo das FT}


As FT são classificadas, de forma não excludente, de acordo com os critérios:

1) pragmático (CARREIRA, 1995; BALSALOBRE, 2010), que organiza as FT em função do papel dos interlocutores na interação: elocutivo, alocutivo e delocutivo e;

2) morfológico, que é dado pelas classes de palavras as quais pertencem as FT: pronominais; verbais e nominais (CINTRA, 1962; BRAUN, 1988).

$\mathrm{Na}$ classificação pragmática, o termo elocutivo compreende a designação de si, quem enuncia; aquele que fala, é uma autorreferência. Entre as maneiras postas em açáo para designar aquele que enuncia, os pronomes eu, nós, a gente e suas conjugaçôes verbais parecem ser as mais utilizadas. Em algumas situaçóes já foi detectada a autorreferência na segunda ou terceira pessoas (LAND; KITZINGER, 2007).

Quando nos referimos a um termo alocutivo, significa como nos referirmos ao colocutor, para quem se enuncia, com quem falamos. A língua portuguesa, no quesito sistema de tratamento, tem mostrado um comportamento um pouco diferente de muitas outras línguas que apresentam a dualidade T/V. Além de tu, o você, o/a senhor/a, o/a amigo, o/a professor/a, o/a doutor/a etc., existem os extremamente formais, como Vossa Senhoria ou Vossa Excelência, somente postos em ação em interaçôes hierarquizadas de contextos específicos (jurídico, político) e bastante ritualizados linguisticamente ${ }^{3}$. Um outro caso é a ausência de pronome, ou realização Ø (zero).

Já o delocutivo nomeia como nos dirigimos a quem está fora do circuito interativo, as terceiras pessoas sobre quem enunciamos, de quem falamos. No entanto, esta não foi ênfase deste trabalho e, por isso, será pouco abordado.

As FT Pronominais, como critério morfológico, são a forma mais conhecida e lembrada quando nos referimos aos modos de nos dirigirmos aos nossos interlocutores e de enunciarmos a nós mesmos. Inclusive, é evidente a "falta de homogeneidade na classificação de pronome de tratamento

${ }^{3}$ Como pode ser visto, recentemente, em G1, Bahia: “Não me abati', diz advogada repreendida durante fala no STF por chamar ministros de 'vocês". Disponível em: https://g1.globo.com/ ba/bahia/noticia/2019/11/08/nao-me-abati-diz-advogada-repreendida-durante-fala-no-stfpor-chamar-ministros-de-voces.ghtml. Acesso em: $10 \mathrm{dez} .2019$. 
dada pelos gramáticos" (LOREGIAN-PENKAL, 2006, p. 80), pois a conceituação de pronome não é consenso entre os pesquisadores, sendo que você(s) e o(a) senhor(a), principalmente, oscilam entre classificaçóes como formas de tratamento ou como pronomes de tratamento.

No português antigo, a divisão entre a dimensão familiar/íntima e cortesia/polidez não era difícil de ser feita e era polarizada na forma dos pronomes tu $(\mathrm{T})$ e vós $(\mathrm{V})$, assim como várias línguas europeias. É importante notar que uma das línguas mais estudadas, na atualidade, o inglês, não possui a distinção pronominal entre $(\mathrm{T})$ e $(\mathrm{V})$, assim como aparenta não tê-la a Libras. Em inglês, o pronome you serve tanto o contexto de intimidade quando o de polidez, assim como, na Libras, parece comportar-se o apontamento para o interlocutor.

Embora a forma padrão seja você, esta forma de referência ao colocutor, em algumas regióes do Brasil, possui as variantes ocê e cê, consideradas de menos prestígio. Freitas (1997) refere a existência de uma certa polêmica em classificar o você(s) como uma forma de tratamento nominal (originário de Vossa Mercê) ou como um pronome de tratamento, pois alguns dos gramáticos tradicionais alternam-se em registrar estas formas de uma ou outra maneira.

$\mathrm{Tu}$, o pronome original de segunda pessoa singular, nos dias atuais, concorre com você no tratamento ao colocutor e, apesar de minoritário, em uso, persiste em algumas regióes do Brasil. Pesquisas recentes apontam para uma alternância entre o tu e o você em todas as regióes do país (SCHERRE; MODESTO, 2009, 2010; YACOVENCO, 2011). Loregian-Penkal (2004), encontra, inclusive, uma grande variação na própria região Sul, na qual é tido como dominante.

Outra modificaçáo no PB falado, que vem trazendo instabilidade ao sistema pronominal, é a gramaticalização de a gente. A gente é uma das expressóes mais controversas, ora incluída na classe dos pronomes pessoais e ora como pronome indefinido (MONTEIRO, 1990; LOPES, 2003). Lopes (2003) identifica a sua evolução da seguinte forma: gente [nome genérico] $\rightarrow$ a gente [pronome indefinido] $\rightarrow$ a gente [pronome pessoal].

No entanto, quando se fala em FT, nem sempre a correspondência do termo formal com a pessoa discursiva apontada é unívoca. Existem casos documentados de língua falada em que a referência formal a um pronome é indeterminada. Por exemplo, o caso do pronome nós, que pode representar: "eu+você, eu+ele, eu+vocês, eu+eles, eu+todos" (LOPES, 2007, p. 8) ou a pessoa indeterminada e "plural de modéstia" (ILARI et al., 2002). O 
que acontece é que o quadro de pronomes pessoais, que ainda vigora nas gramáticas, estruturado a partir de três pessoas do discurso (eu/tu/ele), com variação de número (nós/vós/eles), está longe de ter uma coerência interna e de dar conta da realidade concreta do português do Brasil (LOPES, 2007, p. 4).

A categorização morfológica das FT Verbais é afetada pela crescente alternância entre o tu e o você, e entre o nós e a gente, produzindo modificaçóes, tanto no sistema pronominal como, consequentemente, no sistema verbal do PB. Estas alteraçóes, ainda em curso e pouco reconhecidas pelos partidários da gramática normativa, são consideradas ora como "erros", ora como desvios da gramática tradicional. No Quadro 1, trazemos uma comparação entre a forma ensinada na maioria dos manuais escolares e o seu estágio atual no PB.

\begin{tabular}{|c|c|}
\hline FORMA PADRÃO & PB \\
\hline EU escrevo & EU escrevo \\
\hline TU escreves & $\begin{array}{c}\text { TU escreves } \\
\text { VOCÊ escreve }\end{array}$ \\
\hline ELE/ELA escreve & ELE/ELA escreve \\
\hline NÓS escrevemos & NÓS escrevemos $\rightarrow$ A GENTE escreve \\
\hline VÓS escreveis & VOCÊS escrevem \\
\hline ELES/ELAS escrevem & ELES/ELAS escrevem \\
\hline Quadro 1 - Comparação entre a desinência verbal ensinada nas gramáticas normativas \\
\hline
\end{tabular}

Atualmente, há um movimento de diminuição nas formas de flexão verbal. Considerando que a segunda pessoa do singular, tu, geralmente é conjugada com a forma verbal na terceira pessoa do singular, diminuímos para cinco terminaçóes verbais e se contarmos com a crescente substituição de nós por a gente, conjugado também na terceira pessoa do singular, teremos, entáo, quatro terminaçóes verbais atuantes no PB contemporâneo. Antigamente, o PB apresentava um paradigma verbal mais rico e a concordância permitia recuperar o sujeito mas, atualmente, cada vez mais a explicitação do sujeito tem se tornado necessária, o que torna a utilização de 
FT verbais mais raras.

E, finalmente, na classificação morfológica das FT nominais, são os substantivos e os adjetivos utilizados para designar ou referir o colocutor (BRAUN, 1988), assim "[...] o uso nominalizado lembra algo próprio da pessoa com quem se fala, seja simplesmente o sexo, seja a categoria social ou profissional, o parentesco, o grau de intimidade entre os interlocutores etc." (BALSALOBRE, 2010, p. 92). Na língua escrita, existe uma lista prolífica de FT nominais, que são tradicionalmente estudadas para normas de correspondência comercial e jurídica, tais como Vossa Excelência, Vossa Senhoria, Vossa Magnificência etc. Na língua falada, entre uma grande variedade de tipos de nomes de tratamento, as mais frequentes são: nomes em geral e em especial nomes próprios, termos de parentesco e intimidade (pai, mana, amigo, camarada etc.), honoríficos (senhor/a, vossa excelência etc.), título profissional ou de função (professor/a, coronel, princesa etc.), entre outros. Boa parte destes termos pode ser antecedida, seguida ou combinada de diversas formas entre si, como, por exemplo, senhor diretor.

\section{As FT nas línguas de sinais e na interpretaçáo interlíngue}

Embora este estudo seja das produçôes da interpretação interlíngue em $\mathrm{PB}$, precisamos considerar também algumas particularidades das línguas de sinais, como as enunciaçôes originárias, a partir das quais os ILS vão trabalhar. Investigaçóes conhecidas sobre a forma de mencionar outra pessoa, no discurso em línguas de sinais, têm sido feitas mais na perspectiva da dêixis de pessoa realizada por meio de pronomes e verbos indicadores ou com concordância (HOFFMEISTER, 1978; LOEW, 1984; PETITO, 1986; BERENZ, 1996; MOREIRA, 2007; HAZOPOULOU, 2008; PIZZIO; REZENDE; QUADROS, 2009) do que, propriamente, da perspectiva das FT.

A única referência direta às FT em línguas de sinais, com a qual me deparei, foi em Roncarati (2008), mencionando um trabalho de Ferreira Brito (1996), sobre um único exemplo de dêixis social em Libras: "uma forma pronominal de terceira pessoa do singular que tanto identifica o referente, quanto sinaliza que a pessoa referida não é intimamente próxima" (RONCARATI, 2008, p. 126). Sendo que não houve descrição do sinal e, portanto, não consegui identificar que forma pronominal ela seria.

Moreira (2007), em uma exaustiva revisão bibliográfica, afirma que 
a dêixis de pessoa, em línguas sinalizadas, é realizada substancialmente por meio de dois tipos de sinais de apontamento: os pronomes pessoais e os verbos indicadores ou com concordância. A referência de pessoa, nas línguas de sinais, é sempre marcada espacialmente, ou seja, é realizada no espaço físico e depende dele. $\mathrm{O}$ grande traço diferencial entre a segunda e a terceira pessoas é que, na segunda pessoa, o apontamento é direcionado diretamente para o colocutor e conjuntamente com a mesma direção do olhar.

$\mathrm{O}$ PB demonstra ter um sistema de dêixis social mais complexo do que a Libras. Não seja tomada esta afirmativa como uma generalização de que a Libras é menos complexa, mas apenas como um dado comparativo entre línguas. Assim como a Libras, a língua inglesa não possui a distinção entre $(T)$ e $(V)$.

A interpretação interlíngue possui mais uma característica determinante: um dos participantes da interação fala pelo outro e, na maioria das vezes, como se fosse o próprio outro por meio da autorreferência ou, mais apropriadamente, da FT elocutiva. Interpretar na primeira pessoa ou reter a perspectiva de pessoa (BOT, 2005) é um dos aspectos mais intrigantes e, paradoxalmente, menos estudados, tendo em vista sua consideraçáo como indicador de qualidade da interpretação. Um dos poucos textos que se ocupam do assunto é um estudo realizado por Pöchhacker (1995), a partir da observaçáo de como os intérpretes de alemáo e inglês gerenciavam as FT no congresso do Conselho Internacional para Pequenos Negócios (International Council for Small Business - ICSB). Foi verificada a necessidade de um cuidado ao utilizar as FT, pois, sendo termos intimamente ligados à cultura, há dificuldade e, em alguns casos, impossibilidade de interpretar os termos e títulos para a outra língua. O efeito causado na plateia, pela utilização de uma FT menos polida, pode ser delicado e constrangedor aos interlocutores, ao mesmo tempo que uma FT com um grau de polidez exacerbado pode causar a impressáo de pedantismo ou arrogância. Vejamos o exemplo:

\begin{tabular}{|c|c|}
\hline FT em inglês (língua fonte) & $\begin{array}{c}\text { O intérprete diz em alemão } \\
\text { (língua alvo) }\end{array}$ \\
\hline Bruce (primeiro nome) & Präsident (Presidente) Kirchhoff \\
\hline Mister Hinteregger & Botschafter (Embaixador) Hinteregger \\
\hline Em geral, a FT utilizada era o primeiro \\
nome. & $\begin{array}{c}\text { Em geral, a FT utilizada era Herr (senhor) ou } \\
\text { Frau (senhora). }\end{array}$ \\
\hline
\end{tabular}

Quadro 2: Amostra de algumas FT utilizadas na interpretação do inglês para o alemão (PÖCHHACKER, 1995) 
Desta pequena amostra, é possível inferir que a utilização das FT, em alemão, são bem mais complexas e estão sujeitas a mais condiçôes hierárquicas do que na língua inglesa.

Sem um escrutínio do intérprete sobre a interação, sobre os interlocutores, sobre o que os interlocutores sabem entre si e sobre si e quais as expectativas que cada um tem do outro e da própria atividade dos intérpretes interlíngues, não é possível uma utilização satisfatória das FT.

\section{Metodologia}

O recorte de pesquisa considera as interaçôes mediadas por intérpretes de Libras, com a direcionalidade da Libras para o Português Brasileiro (PB), em contexto educacional de ensino superior. Utilizei uma triangulação de dados, baseada em análises de filmagens, em uma entrevista com cada ILS, bem como os elementos de um estudo de caso, sendo sua unidade de análise uma universidade federal, localizada no Rio Grande do Sul, que identificarei como sendo a Universidade Federal dos Açudes. Após as filmagens, entrevistei as ILS para obter um maior detalhamento sociolinguístico e para que cada uma justificasse a sua escolha pelas formas de tratamento que utilizaram. Este encontro, posterior às filmagens, serviu também para a qualificação das transcriçóes e traduçóes das interaçóes tornando as ILS cotranscritoras.

Neste trabalho, para fins de análise, considero o critério morfológico como subjacentes ao critério pragmático. Não examinarei as FT delocutivas, embora, inicialmente, existisse a possibilidade de, em uma interpretação interlíngue, os ILS utilizarem a terceira pessoa para se referirem aos seus colocutores secundários surdos. Entretanto, isso praticamente não ocorreu e só analiso o uso de formas sujeito de tratamento, descartando as formas vocativo e objeto (que inclui os pronomes oblíquos).

Uma sucinta caraterização do perfil dos participantes:

- Takk ${ }^{4}$ : técnica administrativa em educação (TAE), tradutora e intérprete de língua de sinais (ILS). Escolaridade: graduanda. Faixa etária: 20 a 30 anos. Formação para a ILS: nenhuma formal, somente em serviço na instituição religiosa da qual é seguidora.

${ }^{4}$ Todos os pseudônimos escolhidos significam agradecimento em diferentes línguas: Takk (norueguês), Kiitos (finlandês), Spasibo (russo, transliterado), Multsumesc (romeno, transliterado), Arigatô (japonês, transliterado) (ABER, 2008). 
- Arigatô: técnica administrativa em educação (TAE), tradutora e intérprete de língua de sinais (ILS). Escolaridade: mestrado. Faixa etária: 20 a 30 anos. Formação para a ILS: curso de extensão de 360 horas e em serviço na instituição religiosa da qual é seguidora.

- Kiitos: acadêmico surdo. Escolaridade: ensino médio. Faixa etária: 20 a 30 anos.

- Multsumesc: docente surdo. Escolaridade: mestrado. Faixa etária: 30 a 40 anos.

- Spasibo: docente surdo. Escolaridade: doutorado. Faixa etária: 50 a 60 anos.

A maioria das pessoas ouvintes e, às vezes, algumas pessoas surdas, que estavam no ambiente físico da interação e nem sempre diretamente envolvidas na troca linguística em si, foram consideradas pela característica desta investigação em enfatizar a direção de interpretação da Libras (pessoa surda) para o PB (ILS), como coadjuvantes e referidos genericamente.

Foram filmadas situaçóes reais de interaçáo, com o objetivo de preservar ao máximo as características da fala espontânea, das quais obtive quatro cenários:

- Reunião: os primeiros vídeos foram filmados em uma reunião de professores do departamento, em que são lotados os dois professores surdos de Libras. Participantes: Spasibo (professor surdo), 22 professores, uma secretária, 2 ILS (Arigatô, atuando, e Takk, como participante secundária, no apoio), bem como a pesquisadora, participando da reunião, filmando.

- Entrevista: este vídeo foi decorrente da necessidade de uma aluna de graduaçáo em Pedagogia entrevistar um acadêmico surdo para o seu Trabalho de Conclusão de Curso (TCC). Participantes: ILS: Arigatô. Pessoas surdas: Kiitos. Pessoas ouvintes: acadêmica de Pedagogia, 1 ILS (Arigatô) e uma amiga da acadêmica, somente filmando.

- Aula: todos os vídeos são resultado de uma mesma aula. Participantes: ILS: Takk. Pessoa surda: Multsumesc. Pessoas ouvintes: 27 alunos e a pesquisadora, somente filmando.

- Palestra: ILS: Arigatô. Pessoa surda: Multsumesc. Pessoas ouvintes: uma plateia com, aproximadamente, 60 pessoas, incluindo a 
pesquisadora.

As transcriçóes foram feitas no ELAN (EUDICO Linguistic Annotator $)^{5}$, que é uma ferramenta de notação multimídia de áudio e vídeo, desenvolvida pelo Instituto de Psicolinguística Max Planck (Holanda), sendo muito utilizada em trabalhos que abordam as línguas de sinais e as convençôes adotadas são as mesmas que foram utilizadas no Projeto Bibibi $(\text { Bilíngue bimodal })^{6}$. Os itens que mais interessam nesta pesquisa são aqueles que descrevem o apontamento para pessoas: IX, seguido pelo referente, com letras minúsculas, dentro de parênteses. Exemplos:

- IX(si): apontamento para si.

- IX(professora): apontamento para a professora.

- IX2(vocês): vocês dois. IX por ser um tipo de indexação, "2" por ser a configuração de mão do número 2 e "vocês" por ser a segunda pessoa do discurso.

- IX2(eles) para "eles dois" e assim sucessivamente para com os numerais três e quatro: IX3(nós), IX3(vocês), IX3(eles), IX4(nós), IX4(vocês), IX4(eles).

Neste artigo, por abordar diálogos, disponibilizo a análise das interpretaçóes para o PB nas categorias: FT elocutivas, quando o enunciador é o protagonista e FT alocutivas, quando entra em cena o coadjuvante, o colocutor.

\section{Análise e discussáo}

$\mathrm{Na}$ apresentação dos resultados, utilizarei o seguinte padrão:

Evento, tempo de detecção no vídeo.

Pessoa surda: transcrição do ELAN da sinalização em Libras.

ILS: interpretação para o português brasileiro.

Comentário: justificativa da utilização da FT ou qualquer outra observação que as ILS quisessem fazer.

5Disponível em: http://tla.mpi.nl/tools/tla-tools/elan. Acesso em: 17 mar. 2020.

6Disponível em: http://nals.cce.ufsc.br/?page_id=58. Acesso em: 20 mar. 2020. 
As FT elocutivas mais encontradas foram a primeira pessoa do singular e a forma verbal flexionada correspondente na situação em que a pessoa surda fazia, explicitamente, o apontamento para si, e a ILS interpretava em $\mathrm{PB}$ como eu ou com a conjugação verbal.

Palestra, 0:51

Multsumesc: IX(si) PENSAR COMBINAR IGUAL.

Arigatô: eu concordo plenamente com o conhecimento da professora.

Comentário: ah... é pelo prestígio de ser uma professora, palestrante, famosa, já aposentada.

Arigatô considera esta repetição algo indesejável e diz "eu poderia ter evitado". A questáo que permanece é que, na verdade, este tipo de repetição é bem corriqueiro em discursos da língua falada e somente é considerado como uma falha por algumas linhas prescritivistas e, principalmente, é uma regra ensinada quanto à língua escrita. É considerada redundância a repetição do pronome, porém, na prática, vê-se que "embora não se possa dizer que perdemos a possibilidade de omitir o sujeito, observa-se clara preferência pelo uso da forma pronominal plena" (DUARTE, 1995, p. 4), mesmo que considerada, a princípio, antiestética. Esta marcação do eu, repetida, não se deve somente a questóes gramaticais. É preciso mostrar o destaque de quem está falando, assumir a posiçáo de quem enuncia e reforça, pela voz, ser a figura principal da interlocução.

\footnotetext{
Por isso é importante ver que o eu [self] é, em parte, uma coisa cerimonial, um objeto sagrado que precisa ser tratado com o cuidado ritual apropriado e que, por sua vez, precisa ser apresentado aos outros sob a luz apropriada. Enquanto um meio através do qual este eu é estabelecido, o indivíduo age com porte apropriado enquanto está em contato com os outros e é tratado pelos outros com deferência (GOFFMAN, 2011, p. 90).
}

Mesmo quando náo é marcado com um apontamento, por ser um diálogo entre duas pessoas, a ILS assume que a pessoa surda está falando por si mesma e introduz o eu no PB como marca da subjetividade do locutor primário surdo, vejamos: 
Entrevista, 1:08-1:11

Kiitos: POR-QUE ANTES DV(tamanho-pequeno) IX(mãe) PEDIR+ CARINHO DV(carinho-orelha) SURDO IX(eles) VELHO[?] PERCEBER SINAL POSS(eu) SINAL-PRÓPRIO.

Arigatô: porque, antigamente, quando eu era criança, eu sempre pedia para minha mãe.

Comentário: o sujeito que ele indicou era ele mesmo, é contextual.

Kiitos não faz nenhum apontamento explícito para si, mas a entrevistadora pergunta a motivação de seu sinal pessoal (sinal próprio) e, evidentemente, o relato é de sua vida e das circunstâncias que geraram aquele sinal. Para Arigatô, o ambiente contextual de Kiitos, ao relatar sobre sua vida, é o desencadeador destas referências explícitas ao eu.

Uma das poucas ocasióes em que podemos omitir o pronome sujeito e ficar plenamente elicitado a pessoa discursiva é o caso das primeiras pessoas singular e plural (quando utilizada a forma canônica nós) e na terceira pessoa do plural. Nos outros casos, se utilizada a desinência de terceira pessoa do singular, pode haver uma indeterminação de qual pessoa estamos nos referindo, pois a gente também pede o verbo na terceira pessoa do singular e em muitos casos de utilização do tu ocorre, também, esta última desinência. Então, é um caso em que fica bem claro e confortável para a ILS utilizar-se somente do verbo conjugado e, ainda assim, marcar bem o eu do locutor primário, como é possível perceber neste excerto:

Aula, 0:22

Multsumesc: CONHECER.

Takk: conheço.

Comentário: não precisava o pronome, está implícito na conjugação verbal, né?

Houve ocorrências de interpretação zero (Ø), quando nenhuma referência é utilizada, como em:

Entrevista, 26:03

Kiitos: BOM NADA2 BOM PRAZER EMOÇÃO VIDA CONTAR 
IX(vocês) IX(nós) BOM XXX CONHECER PRAZER IX(nós). Arigatô: de nada [risadas] também foi um prazer tá aqui [essas informaçôes, essas histórias?] e tal, né? Comentário: eu não usei o nós porque parecia muito geral.

Kiitos sinaliza de forma clara; nós, o que pode ser indício de uma estratégia de generalização em Libras ou indeterminação. Tanto pode ser uma referência a nós, surdos, nós, acadêmicos surdos, ou eu + qualquer um ou alguém. Arigatô decide por um discurso mais informal, sem enunciar o eu, mas, de certa forma, assumindo-se como tal.

No fim da entrevista propriamente dita, os locutores primários e a ILS começam uma conversa mais descontraída. A aluna entrevistadora trouxe uma outra moça que ficou encarregada somente da filmagem. Esta moça não foi apresentada e a pessoa surda fica curiosa quanto a sua presença e diz: "estou pensando, quem é ela?" e pergunta se ela veio para ajudar, em Libras, nos dois excertos a seguir:

\section{Entrevista, 26:47}

Kiitos: PENSAR QUEM IX(ele).

Arigatô: $\varnothing$ não é da pedagogia?

Comentário: foi uma situação muito constrangedora, eu não sabia quem era a acompanhante da aluna, pareciam namoradas.

\section{Entrevista, 26:50}

Kiitos: AJUDAR É AJUDAR É IX(ele).

Arigatô: $\varnothing$ veio ajudar?

Comentário: (risadas) deixei meio em aberto quem seria, quem quisesse respondesse.

Como vemos nos excertos, Arigatô evita o pronome (tu veio ajudar, você veio ajudar, ela veio ajudar?) e, assim, pelo seu comentário, deixa a tarefa da decisão de quem iria responder em aberto (a aluna ou sua acompanhante). Esta parece ser uma estratégia conhecida, pois Manole (2013) afirma que, para evitar situaçóes delicadas, se evita o pronome, empregando apenas o verbo conjugado, desviando-se assim de uma referência táo direta ao interlocutor. 
$\mathrm{Na}$ continuidade da conversa, as despedidas demoram-se entre as perguntas pessoais, sobre os estudos e muitos agradecimentos, de ambas as partes. A ILS, nesse momento, opta por ser mais direta, mais sucinta e elimina o eu, trocando-o por uma frase praticamente formulaica, "obrigado pelo convite".

Entrevista, 26:13

Kiitos: IX(si) MUITO OBRIGADO IX(vocês) XXX e(positivo) NADA2.

Arigatô: $\varnothing$ obrigado pelo convite.

Comentário: ah, ali era só encerrar a conversa.

Outra possibilidade para este uso está no fato de que

"os agentes responsáveis por conduzir as ações descritas podem ser omitidos porque eles são conhecidos e, portanto, a especificaçáo seria redundante ou, por outro lado, podem ser deixados não especificados para omitir alguma informação da audiência”" (CECCHETTO; STROINSKA, 1996, p. 782).

Em muitos casos, o pronome não é explicitado porque já está ancorado, anteriormente, e a ILS quer evitar repetiçóes. Devemos lembrar que a interpretação interlíngue é feita sob a pressão do tempo, com pouca margem para a tomada de decisóes.

Reunião, 0:10

Spasibo: SINAL-PRÓPRIO IX(pessoa) IX(lista-dois) SINALPRÓPRIO IX(pessoa) SINAL-PRÓPRIO IX(pessoa) IX(pessoa) IX(lista-mão) CERTO IX(si) e(esperar)/.

Arigatô: $\varnothing$ a (nome de pessoa), a (nome de pessoa), o (nome de pessoa) e a (nome de pessoa).

Comentário: repetiu uma informação já dada, por isso não repeti.

${ }^{7}$ No original: The agents responsible for carrying out the actions described may be omitted because they are known and thus the specification would be redundant, or alternatively, they may be left unspecified to conceal some information from the audience (CECCHETTO; STROINSKA, 1996, p. 782). Tradução livre de MARIA CRISTINA PIRES PEREIRA. 
A informação já dada foi a repetição de uma lista que Spasibo já havia mencionado antes. Diante da possibilidade de ter que repetir toda a lista, Arigatô assume que, como a pessoa que estava sinalizando já havia mencionado a si mesma, poderia ser ocultada para evitar a repetiçáo e, talvez, uma excessiva menção a si mesma.

Em certas passagens, ocorre uma referência mista de primeira pessoa. No excerto a seguir, eu e a gente aparecem intercalados ou repetidos. As ILS escolhem diminuir as mençôes explícitas a eu e alterná-las com a gente, ou mesmo em suprimi-las.

Entrevista, 1:37-1:58

Kiitos: CERTO IX(si) ANTES XXX PROVA IX(si) PENSAR CURSO[?] IX(si) AMOR MAIS TEATRO IX(si) MAS DIFÍCIL TERNÃO NOITE TER-NÃO SÓ ACORDAR[?] TARDE2[?] IX(si) TER TRABALHO IX(isso) IX(si) PENSAR IX(si) e(fazer-tempo) [?] IX(si) JÁ OUTRO OUVIR DV(ir-todo-lugar) PROBLEMA ACONSELHAR JÁ IX(si) e(fazer-tempo) FS(eca)+.

Arigatô: antigamente, na verdade, no vestibular, na prova que a gente fazia [inaudível], eu sempre gostei muito da artes cênicas, teatro, muito difícil porque não tinha noturno só diurno e eu trabalho durante né o dia e aí alguns outros ouvintes ahn me falaram como... sobre a questão do ECA.

Comentário: é muita repetição dele se apontar, optei por não traduzir, ia ficar muito repetitivo. E o a gente é porque...porque náo era só ele que fazia o vestibular.

Se, na Libras, como língua praticamente só falada, sem uma cultura de escrita, as repetiçóes fazem parte do discurso, no $\mathrm{PB}$, provavelmente por influência da escrita, as repetiçôes são, na medida do possível, constantemente evitadas.

$\mathrm{Na}$ sequência, Kiitos, comentando sua prova do ENEM (Exame Nacional do Ensino Médio), faz duas vezes o sinal de PASSAR (ser aprovado), na primeira vez sem o apontamento para e na segunda vez com o apontamento. Novamente, evitar a repetiçáo é a motivação da ILS para omitir um dos pronomes possíveis: 
Entrevista, 2:08

Kiitos: IX(si) GOSTAR2 IX(si) ESCOLHER BOTAR ESPERAR XXX PASSAR DEPOIS2 FACULDADE COMEÇAR DOIS ZERO DEZ DOIS ZERO DEZ AGOSTO2[?] COMEÇAR IX(si) ESTUDAR AMOR VONTADE INTERESSAR ÓTIMO3 BOM SINAL-PRÓPRIO.

Arigatô: em agosto de 2010 eu comecei né.

Comentário: mesma coisa, não quis repetir muito, não fica bem ficar toda hora eu, eu, eu.

Um conhecido fenômeno, que é cada vez mais documentado no PB, é a gramaticalização de gente como nome, para a gente, pronome. Supóemse a existência de um "falante + alguém" (variante de nós), uma espécie de "eu-ampliado" (BENVENISTE, 1995). Esta forma pronominal emergente coexiste com a mais antiga, nós, porém, nas últimas décadas, a primeira forma vem sendo cada vez mais utilizada (LOPES, 2003).

A ocorrência da forma pronominalizada de a gente foi frequente nos dados analisados.

Reuniấo, 0:50 a 0:55

Spasibo: VERDADE VIR MAS2 OUTRO+ XXX IX(si) NÁO CONVIDAR FS(com) VAI FS(te) IX(você) QUERER INTERESSAR NĀO ACHAR3 JÁ COMEÇAR IX(nós) JÁ COMEÇAR TRABALHAR DEPOIS GRUPO DV(grupo-vir) e(depois) ESCOLHER XXX DEPOIS PRA-FRENTE[?] e (tantofaz).

Arigatô: os outros, mas a gente já pode iniciando [quase inaudível] os trabalhos, depois a gente pode marcar...

Comentário: ele estava falando com colegas de trabalho, em uma atividade corriqueira [reunião], não era uma palestra, era um diálogo com os colegas.

As duas formas pronominais mais frequentes foram, sem dúvida, eu e a gente. A gente ainda é considerado, pelas ILS, como uma expressão coloquial, informal e aproximativa, que indica uma certa familiaridade com o interlocutor. Considerando que "um procedimento para verificar se 
uma forma linguística tem prestígio social é observar ou mesmo solicitar às pessoas das comunidades estudadas que expressem seu julgamento sobre tal emprego" (ZILLES, 2007, p 36), na interpretação para o PB, em geral, as ILS justificam o uso de a gente em nome de uma informalidade, de uma conversa entre iguais, consequentemente marcada pela solidariedade.

V5, 1:54

\section{Multsumesc: AGORA INTÉRPRETE IX(ele) INTÉRPRETE TAMBÉM FIM FECHAR-PORTA AULA LER COMO CONVERSAR.}

Takk: agora então ahn a gente vai ter uma interp...a presença da intérprete.

Comentário: ah era uma situação informal, com os alunos, acho que a gente fica mais...coloquial, né?

Outro fator que pode ter influenciado na maior opção pelo a gente é o uso mais relaxado no contexto institucional do ensino superior:

[...] tenho observado uma grande informalidade no tratamento entre professores e alunos, professores e professores, professores e funcionários, professores e dirigentes, o que pode ser um reflexo da própria estrutura universitária em que todas as posiçóes hierárquicas são provisórias, isto é, o reitor de hoje foi ontem um professor qualquer e findo seu mandato voltará a ser um professor qualquer (MENDES, 1998, p. 137-138).

Por outro lado,

herdando talvez o traço indeterminado do substantivo gente, a gente integrase ao sistema pronominal concorrendo com nós. Na verdade, postula-se que a gente resultou do seguinte processo: gente [nome genérico] $\rightarrow$ a gente [pronome indefinido] $\rightarrow$ a gente [substituto virtual do pronome pessoal nós]. A forma plural nós também permite leituras interpretativas diversas que vão desde uma determinação precisa, como eu +você ou eu + ele, até um grau máximo de indeterminação e generalidade: eu + todo mundo ou eu + qualquer um (LOPES, 2004, p. 73).

Além da referência óbvia a um conjunto de eus, a FT pronominal nós também remete a um discurso mais estético, mais prestigiado e que as ILS julgaram necessário utilizá-lo para valorizar a fala das pessoas surdas. 
Palestra, 0:23

Multsumesc: CLARO ENTENDER IX(nós) VER g(absorver) g(ansiedade) g(absorver) IX(ele) CULTURA POSS(dele) PRÓPRIA $\mathrm{g}(\operatorname{sim})$.

Takk: claro que nós sabemos que vocês ahn ::: vocês [inaudível] têm aquela coisa com professor surdo...porque em qualquer outra língua, né? Vocês olham e é a cultura e pergunta e aproveita mais coisas além da língua:: né...

Comentário: parece que ele está falando algo mais, algo mais...formal, didático, daí eu usei o nós porque é mais formal.

Palestra, 2:37

Multsumesc: NÃO-ADIANTAR SEMPRE VER-ME UM MOVIMENTO UM CL(junto-movimento) MOVIMENTO JUNTO DISCUTIR INTERAGIR $\mathrm{g}(\mathrm{sim})$.

Arigatô: então nós precisamos também continuar com esta discussão.

Comentário: "nós" fica mais bonito para um fechamento.

Em alguns casos, o nós é considerado uma FT pronominal mais formal, mais culta, reservada para falas de mais prestígio.

Resumidamente, a forma elocutiva pode ser referenciada de diversas maneiras, além do clássico pronome pessoal eu: (1) o PB nos permite utilizar somente a forma verbal, em alguns casos, (2) podemos utilizar construçôes frasais que eliminem a menção formal ao eu, (3) a forma pronominalizada a gente vem crescendo como uma referência generalizante ou indeterminada e (4) com menor incidência, o pronome pessoal de primeira pessoal do plural ainda é utilizado em construçóes consideradas como mais formais, pelas ILS.

As possibilidades de interpretação da Libras para o $\mathrm{PB}$, em termos de FT elocutivas, pode ser sistematizada no quadro a seguir: 


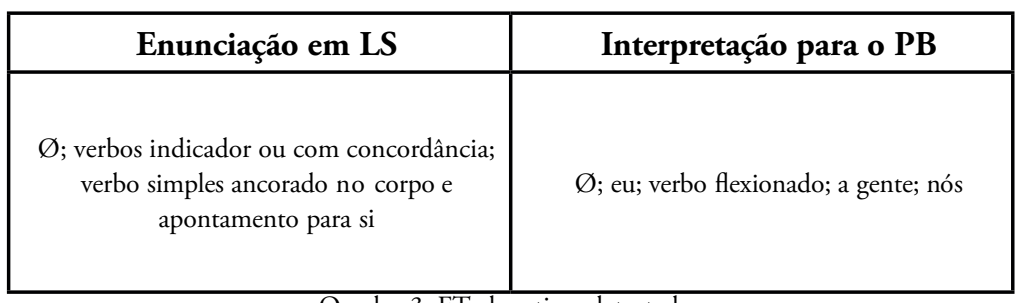

Quadro 3: FT elocutivas detectadas

A categorização pragmática alocutiva, para nos referirmos aos nossos colocutores, ocorreu no evento da palestra, principalmente, com os honoríficos a senhora e a professora.

Palestra, 1:09

Multsumesc: POLÍTICA PROPOSTA TROCAR BILÍNGUE ESCOLA PENSAR INFORMAR FIM IX(si) INFORMAR.

Arigatô: não sei se a senhora soube.

Comentário: é uma senhora de idade, tem prestígio acadêmico.

A palestrante é uma professora, já madura, aposentada, bastante conhecida da Universidade dos Açudes. A senhora é sempre utilizada quando Multsumesc se refere à ela. Isto se deve à justificativa de que "a forma senhor tende a ser empregada em situaçóes de maior monitoramento, maior tensão e menos envolvimento entre os interlocutores" (Modesto, 2005, s/p).

Os fatores extralinguísticos são decisivos na escolha final de como será feito o tratamento, no caso de haver mais de uma opçáo possível para nos referirmos ao nosso colocutor. Consequentemente, as formas de tratamento são guiadas, prioritariamente, por questóes sociais, além das linguísticas. Os interlocutores calibram constantemente as suas FT, de acordo com o "tipo de relacionamento que o usuário percebe ou supóe existir entre ele e seu interlocutor" (MENDES, 1998, p. 137).

Há indícios de que a professora é utilizado no mesmo viés do que a senhora como um honorífico de deferência, formalidade e polidez, marcando uma relação assimétrica, de distanciamento.

Palestra, 0:39 
Multsumesc: POR-EXEMPLO IX(você) DENTRO.

Arigatô: mesma linha, né, que a professora [nome da professora].

Comentário: ele estava falando em público e colocar tu/tua ia parecer muito íntimo de alguém que ele não conhecia.

Palestra, 5:18

Multsumesc: SE DT(raro) ÁREA IGUAL PENSAR INCLUSÃO ACONTECER PROBLEMA VERDADE CONCORDO ASSIM.

Arigatô: eu acho que eu concordo com o posicionamento da professora.

Comentário: colocar um nome pessoal diretamente sem um tratamento ia ficar muito íntimo e eu sei que eles não têm intimidade, não se conheciam e, também, a faixa etária, né? Ela é uma senhora! ah...é pelo prestígio de ser uma professora, palestrante, famosa, já aposentada...

Nas duas formas, a senhora e a professora, fica a interrogação: se o professor surdo se dirigisse diretamente à professora ouvinte, a palestrante, utilizaria estes termos mais formais ou se a relação seria recíproca, entre os dois docentes, mesmo que um fosse mais velho e mais experiente do que o outro. É preciso considerar que a escolha na utilizaçáo destas FT foi realizada pela ILS, não docente (TAE), mais jovem e em posição inferior na hierarquia de uma universidade (docentes, técnicos, alunos e servidores terceirizados).

Quanto às ocorrências de: tu, vocês(s) e verbos flexionados respectivos, podemos destacar que, em alguns casos, vemos um uso típico do tu, muito utilizado na região Sul do Brasil.

Entrevista, 26:40

Kiitos: AGORA PEDAGOGIA IX2(vocês) JUNTO IX2(vocês).

Arigatô: tu és da pedagogia, vocês duas junto são da pedagogia, não?

Comentário: que situação! Tentei deixar a pergunta só para ela [a aluna], mas ele fez, de novo, vocês duas. 
É importante notar a flexão formal do verbo equivalente à segunda pessoa do singular. Isso denota uma preocupação com a correção gramatical e com a imagem do locutor primário, uma pessoa surda.

Um fenômeno digno de nota é que não foi encontrada nenhuma ocorrência de você, o que dá suporte às afirmaçóes de que "o pronome tu é notadamente muito usado na região sul do Brasil até os dias atuais, o que já não ocorre em outras regióes do país com a mesma frequência" (QUEIROZ, 2011, s/p).

Quanto às ocorrências de interpretaçóes das FT alocutivas, temos o seguinte quadro sintético:

\begin{tabular}{|c|c|}
\hline Enunciaçáo em LS & Interpretaçáo para o PB \\
\hline $\begin{array}{c}\text { Ø; verbo indicador ou com concordância, } \\
\text { verbo simples, apontamento para colocutor }\end{array}$ & $\begin{array}{l}\varnothing ; \text { tu; vocês(s) e respectivos verbos; } \\
\text { honoríficos: a senhora, a professora }\end{array}$ \\
\hline
\end{tabular}

Quadro 4: FT alocutivas detectadas

\section{Encerramento}

Um grande impacto na formação dos ILS é a reflexão sobre a questão de como se referir ao interlocutor que fala, mas sendo outra pessoa a retextualizar o enunciado, pois se é dito aos intérpretes para se enunciarem como eu, temos que questionar de qual visão de "primeira pessoa" que estão falando, pois pode-se dizer que todas as interpretaçóes para o PB das formas elocutivas, verificadas nesta investigação, foram em primeira pessoa, mas não se ativeram à concepção clássica de primeira pessoa do singular como forma canônica e, sim, a uma primeira pessoa discursiva que pode ser indeterminada, generalizante, coletiva etc.

Quanto às FT alocutivas, existem fortes evidências de que as escolhas feitas pelas ILS foram guiadas por fatores sociolinguísticos que levaram em consideração (1) quem era o colocutor primário da pessoa surda, sua posição social, qual sua função na universidade, sua faixa etária etc., (2) qual a relação suposta entre os locutores primários, pessoas surdas e ouvintes, se havia intimidade entre eles, qual a relação de poder entre eles, incluindo-se, ali, as ILS e (3) que tipo de situaçáo estava ocorrendo, se era algo rotineiro e informal (aulas) ou ocasional e mais formal (palestra) etc. 
Ao ampliarmos nossa reflexão sobre o ensino da interpretação interlíngue da Libras para o PB, devemos pensar nas condiçóes que apontam possibilidades das FT e que, no caso das formas elocutivas, foram: evitar a redundância (estilística), maior ou menor formalidade, polidez relativa à faixa etária e poder (hierarquia).

Como já advertia Lyons (1981, p. 288), há muito tempo, não se pode "prever com precisão total se duas pessoas usarão $\mathrm{T}$ ou $\mathrm{V}$ em dada situação com base exclusiva em informaçóes sobre sua classe social, idade, sexo, tendências políticas etc.”. Portanto, a questão não é fornecer fórmulas ou receitas de comportamento, mas ressaltar que os formadores e os intérpretes interlíngues sejam analistas das interaçóes a serem mediadas, pois o que existem são probabilidades e formas mais adequadas de gerenciarmos o contato linguístico e cultural.

Angermeyer (2009), em investigação sobre a interpretação interlíngue, em âmbito jurídico, já apontava para o papel do intérprete interlíngue como crucial na manutenção e regulação da relação de poder entre as variedades de língua em um contexto institucional.

Entende-se, assim, que não é suficiente para o ILS o desenvolvimento intensivo de suas competências linguística, referencial e tradutória. É necessária uma sensibilidade no que concerne às posiçóes sociais ocupadas pelos colocutores primários entre si e sobre qual a situação de interação em curso para, a partir de suas escolhas linguísticas, regular o intercâmbio comunicativo entre as pessoas interpretadas: uma competência sociolinguística discursiva.

Como apontamentos para futuras pesquisas, posso citar:

- Como se dá a referenciação de pessoa em outros contextos situacionais: médico, jurídico, político, nos quais as relaçôes regulam-se por meio de outras normas e relaçóes de poder;

- Como acontece as referências às pessoas fora do eixo conversacional, como a náo-pessoa é representada: terceiros, vocativos, discurso reportado etc.;

- Abordar a questão das FT na interpretação interlíngue da Libras para o PB, sob a ótica do trabalho de face e polidez entre tantas questóes que surgiram deste estudo.

Concluindo, as pessoas surdas e sua língua são representadas pelos ILS. 
Diante disso, pesquisa, atenção e formação em aspectos sociolinguísticos, interacionais e discursivos não podem ser relegados, pois a imagem que a sociedade possui da comunidade surda depende deles.

\section{Referências}

AGER, S. OMNIGLOT: Translation of thanks / thank you in many languages. Disponível em: <https://omniglot.com/language/phrases/thankyou. htm>. Acesso em: 23 jun. 2020.

ANGERMEYER, P. S. Translation style and participant roles in court interpreting. Journal of Sociolinguistics, 13/1, p. 3-28, 2009.

BALSALOBRE, S. R. G. Língua e sociedade nas páginas da imprensa negra paulista: um olhar sobre as formas de tratamento [online]. São Paulo: Editora UNESP; São Paulo: Cultura Acadêmica, 2010. 151 p. ISBN 97885-7983-104- 1. Available from SciELO Books http://books.scielo.org.

BENVENISTE, É. Problemas de Linguística Geral I. Traduzido por Maria da Glória Novak e Maria Luisa Neri. Revisão do Prof. Isaac Nicolau Salum. $4^{a}$. ed. Campinas, SP: Pontes, 1995.

BERENZ, N. F. Person and Deixis in Brazilian Sign Language. Tese (Doutorado em Linguística), Universidade da Califórnia, 1996.

BIDERMAN, M. T. C. Formas de Tratamento e Estruturas Sociais. ALFA: Revista de Linguística, 18/19, 339-382, 1972-1973. Disponível em: $<\underline{\text { ht- }}$ tps://periodicos.fclar.unesp.br/alfa/article/view/3520/3293>. Acesso em: 23 jun. 2020.

BOT, H. Dialogue interpreting as a specific case of reported speech. Interpreting: 7:2, p. 237-261, 2005. Disponível em: $<$ https://books.google.com. br/books?id=y3SdZsumwZwC\&pg=PA77\&lpg=PA77\&dq=Dialogue + in terpreting + as $+a+$ specific + case + of + reported + speech.+ Interpreting\&source $=-$ bl\&ots=baYoXIH4xJ\&sig=ACfU3U33wBStxg7V6iKyFnRbw3c9BUedZQ\&hl=pt-BR\&sa $=X \& v e d=2 a h U K E w j-m \quad$ j8pjqAhWiIbkGHeUZCBsQ6AEwAnoECBEQAQ\#v=onepage \&q=Dialogue $\% 20$ interpreting $\% 20$ as $\% 20 \mathrm{a} \% 20$ specific $\% 20$ case $\% 20$ of $\% 20$ reported $\% 20$ speech. $\% 20$ Interpreting\&f=false $>$. Acesso em: 23 jun. 2020.

BRAUN, F. Terms of Address. Problems of Patterns and usage in various languages and cultures. Berlin: Mouton de Gruyter, 1988.

BRITO, L. F. Dêixis em libras e problemas de aquisição de escrita. III 
Congreso Latinoamericano de Educación Bilíngue para los Sordos. Merida, Venezuela, 1996.

BROWN, R.; GILMAN, A. The pronouns of power and solidarity. In: T. Sebeok (Ed.) Style in Language. Cambridge, Massachussets, M.I.T. Press, p. 253-276, 1960.

CALIFORNIA C. Foreign Language Interpreter's Duties-Civil and Small Claims for Noncertified and Nonregistered Interpreters, 2008. Disponível em: <http://www.courtinfo.ca.gov/forms/documents/int200. pdf>. Acesso em: 12 jan. 2009.

CARREIRA, M. H. A. Les formes d'adresse (formas de tratamento) en portugais contemporain: modalisation linguistique en situation d'interlocution: proxémique verbale et modalités em portugais. Thèse (Doctorat d'État) - Université de Paris IV - Sorbonne, Paris, 1995.

CECCHETTO, V.; STROINSKA, M. Systems of self-reference and address forms in intellectual discourse. Language Sciences: Vol. 18, N. 3-4, p. 777-789, 1996. Disponível em: <https://eprints.kingston.ac.uk/3532/1/ systems of self reference.pdf $>$. Acesso em: 23 jun. 2020.

CINTRA, L. L. Sobre "formas de tratamento" na língua portuguesa. Lisboa: Livros Horizonte, 1986.

DUARTE, M. E. L. A perda do princípio "evite pronome" no português brasileiro. 1995. 151f. Tese (doutorado) - Universidade Estadual de Campinas, Instituto de Estudos da Linguagem, Campinas, SP. Disponível em: $<$ http://www.repositorio.unicamp.br/handle/REPOSIP/270366>. Acesso em: 20 dez. 2019.

FREITAS, J. O Escolar e os Pronomes. Revista Graphos, p. 97-113, 1997. Disponível em: <http://www.repositorio.ufba.br/ri/handle/ri/3295>. Acesso em: 13 mai. 2012.

GOFFMAN, E. Ritual de interaçáo: ensaios sobre o comportamento face a face. Traduzido por Fábio Rodrigues R. da Silva. Petrópolis, Vozes, 2011. HAZOPOULOU, M. Acquisition of Reference to Self and Others in Greek Sign Language: from pointing gesture to pronominal pointing signs. Tese. Department of Linguistics, Sign Language Section, Stockholm University, 2008.

HOFFMEISTER, R. J. The development of demonstratives pronouns, locatives and personal pronouns in the acquisition of American Sign Language by deaf children of deaf parents. Tese (doutorado em Linguística). Universidade de Minnesota, 1978. 
ILARI, R. et al. Os Pronomes Pessoais do Português Falado: roteiro para análise. In: CASTILHO, A. T. de; BASÍLIO, M. (orgs.). Gramática do Português Falado. Volume IV: Estudos Descritivos, p. 73-159.. Campinas, SP: Unicamp, 2002.

KASPER, G. Linguistic politeness: Current research issues. Journal of Pragmatics, 14, p. 193-218, 1990.

LAND, V.; KITZINGER, C. Some uses of third-person reference forms in speaker self-reference. Discourse Studies: vol 9(4), p. 493-525, 2007. Disponível em: <https://journals.sagepub.com/doi/ pdf/10.1177/1461445607079164>. Acesso em 23 jun. 2020.

LOEW, R. C. Roles and Reference in American Sign Language: a developmental perspective. Tese (doutorado em Linguística). Universidade de Minnesota, 1984.

LOPES, C. R. dos S. A inserçáo de 'a gente' no quadro pronominal do português. Frankfurt am Main/Madrid: Vervuert/Iberoamericana, v.18. p.174, 2003.

A gramaticalizaçáo de a gente em português em tempo real de longa e de curta duração: retençáo e mudança na especificação dos traços intrínsecos. Fórum Linguístico: Florianópolis, v. 4, n.1, p.47-80, julho de 2004. Disponível em: < https://periodicos.ufsc.br/index.php/forum/article/ view/7728/7098 >. Acesso em: 23 jun. 2020.

. Pronomes pessoais. In: BRANDÃO, S.; VIEIRA, S. (Org.). Ensino de gramática: descrição e uso. 1 ed. São Paulo: Contexto, 2007, v. 1 , p. 103-114.

LOREGIAN-PENKAL, L. (Re)análise da referência de segunda pessoa na fala da regiáo Sul. Tese (Doutorado em Letras), Universidade Federal do Paraná, 2004.

Pronomes pessoais: conceituação versus uso. Analecta: Guarapuava, v. 7, n. 1, p.71-83, 2006. Disponível em: $<$ https://revistas.unicentro. br/index.php/analecta/article/view/2235/1911>. Acesso em: 23 jun. 2020.

LYONS, J. Linguagem e Linguística: uma introdução. Traduzido por Marilda Winkler Averburg e Clarisse Sieckenius de Souza. Rio de janeiro: Zahar, 1981.

MANOLE, V. Uma língua, várias culturas: algumas reflexóes sobre os aspetos sociolinguísticos na localizaçáo em português brasileiro e em português europeu. RIELMA: Revue Internationale D'études en Langues Modernes Appliquées. Actes du Colloque international "Pour qui traduit-on?" 
(Cluj-Napoca, le 12 octobre 2012). Supplément au numéro 6/2013, p. 53-63, 2012. Disponível em: <https://lett.ubbcluj.ro/rielma/RIELMA no6 2013 Supplement.pdf>. Acesso em: 23 jun. 2020.

MODESTO, A. T. T. Notícias de estudos realizados sobre as formas de tratamento no português brasileiro. Revista Letra Magna: Revista Eletrônica de Divulgação Científica em Língua Portuguesa, Lingüística e Literatura, Ano 02, n.02, p. 1-9, $1^{\circ}$ Semestre de 2005. Disponível em: <http://www. letramagna.com/estudostratamento.pdf $>$. Acesso em: 23 jun. 2020.

. Formas de tratamento e julgamentos de valor. Revela: Periódico de Divulgação Científica da FALS. Ano III - No VI- Out2009/Jan2010, s/p.

MONTEIRO, J. L. Variação no uso dos pronomes pessoais no português do Brasil. Verba: Anuário Galego de Filoloxía, vol. 17, p. 145-157, 1990. Disponível em: <https://minerva.usc.es/xmlui/bitstream/handle/10347/3095/ pg 147-160 verba17.pdf? sequence $=1 \&$ is Allowed $=y>$. Acesso em: 23 jun. 2020.

MOREIRA, R. L. Uma Descrição da Dêixis de Pessoa na Língua de Sinais Brasileira: Pronomes Pessoais e Verbos Indicadores. Dissertação (Mestrado em Linguística). Universidade de São Paulo, 2007.

PETITO, L. From gesture to symbol: the relationship between form and meaning in the acquisition of personal pronouns in American Sign Language. Bloomington, Indiana University Linguistics Club, 1986.

PIZZIO, A. L.; REZENDE, P. L. F.; QUADROS, R. M. de. Língua Brasileira de Sinais V. Material didático, Licenciatura e Bacharelado em Letras-Libras na Modalidade à Distância. Florianópolis: UFSC/CCE, 2009.

PÖCHHACKER, F. Simultaneous Interpreting: A Functionalist Perspective. Hermes: Journal of Linguistics, n. 14, p.31-54, 1995. Disponível em: $<$ https://tidsskrift.dk/her/article/view/25094/22017>. Acesso em: 23 jun. 2020.

QUEIROZ, M. Interpretaçáo Médica no Brasil. Dissertação (Mestrado em Estudos da Tradução). Pós Graduação em Estudos da Tradução, Centro de Comunicação e Expressão, Universidade Federal de Santa Catarina, 2011.

RONCARATI, C. Dêixis social - a designação socialmente referenciada: "sabe com quem você está falando?". In: VOTRE, S.; RONCARATI, C. (orgs.). Antony Julius Naro e a Linguística no Brasil - uma homenagem acadêmica. Rio de Janeiro: FAPERJ/7Letras, p. 115-147, 2008.

SCHERRE, M. M. P.; YACOVENCO, L. C. A variação linguística e o 
papel dos fatores sociais: o gênero do falante em foco. Revista da Abralin: v. eletrônico, n. especial, p. 121-146. 1ª parte, 2011. Disponível em: $<$ https://revistas.ufpr.br/abralin/article/view/32348/20548>. Acesso em: 23 jun. 2020.

SOLOW, S. N. Sign Language Interpreting: a basic resource book. Maryland: National Association of the Deaf/NAD, 1996.

ZILLES, A. M. S. O que a fala e a escrita nos dizem sobre a avaliação social do uso de a gente? Letras de Hoje: Programa de Pós-Graduação em Letras da Pontifícia Universidade Católica do Rio Grande do Sul, Porto Alegre, v. 42, n. 2, p. 27-44, junho, 2007. Disponível em: $<$ http://revistaseletronicas. pucrs.br/ojs/index.php/fale/article/view/2408/1882>. Acesso em: 23 jun. 2020 . 